\title{
A Justificação dos Direitos Sociais e Difusos a partir de Argumentos Comunitaristas
}

\author{
Justification of Social and Diffused Rights from \\ Communitarisnism Arguments
}

Guilherme Camargo Massaúl

André Kabke Bainy ${ }^{2}$

\begin{abstract}
RESUMO
Os direitos sociais e os direitos difusos são frutos da evolução histórico-social, bem como das transformações estruturais ocorridas no Estado e, por conseguinte, no próprio ordenamento jurídico. Embora tais transformações decorram principalmente de aspectos fáticos-históricos, o surgimento de novos direitos traz consigo, também, a ruptura de paradigmas teóricos até então dominantes. Isso fez com que surgissem novas justificações e compreensões teóricas adequadas ao contexto observado a partir da segunda metade do Século XX. Desta feita, a corrente teórica denominada comunitarismo surge como contra-argumento ao liberalismo igualitário e ao libertarianismo, contribuindo para que se compreenda e se justifique as novas circunstâncias histórico-jurídicas. Por conseguinte, os direitos sociais e os direitos difusos encontram sustentação teórico-argumentativa nos autores que se encontram no espectro comunitarista. $\mathrm{O}$ presente estudo visa a apresentar uma breve introdução àquele pensamento, e, após, analisar alguns exemplos extraídos das normas constitucionais que coloquem à prova a hipótese suscitada. A metodologia utilizada foi a hipotético-dedutiva, pois partiu-se da hipótese da adequabilidade teórica comunitarista com o objetivo de se deduzir a sua conformação aos direitos sociais e difusos. Por outro lado, em termos de técnica de pesquisa, o trabalhou utilizou o método bibliográfico.
\end{abstract}

\section{PALAVRAS-CHAVE:}

Direitos Difusos, Direitos Sociais, Teoria da Constituição, Democracia; Atuação Judicial.

\section{ABSTRACT}

The social and diffused rights are fruit of the historical and social evolution, as well as the structural transformations occurred in the Modern State and, therefore, in the legal system itself. Although such transformations acrrue from phatics and historical aspects, the emergence of news rights brings in itself, also, the theory paradigma break until then dominant, This circumstance made that arose new justifications and theory comprehension, appropriate to the context of the second half of the 20th Century. Thus, the theory moviment called comunitarism

\footnotetext{
${ }^{1}$ Professor da Faculdade e do Mestrado em Direito da UFPel; Pós-doutor na PUCRS; Doutor em Direito pela Unisinos; Mestre em Ciências Jurídico-Filosóficas pela Universidade de Coimbra; Especialista em Ciências Penais pela PUCRS; Autor dos livros: Metodologia Jurídica. Do início da ciência do direito ao iluminismo português, editora Atlas; O princípio republicano domundo-da-vidado Estado constitucional cosmopolita, editora Unijuí; O Estado de Direito e as dimensões da res publica, editora Prismas; Princípios Constitucionais e Relações Internacionais, ed. Livraria do Advogado.

${ }^{2}$ Mestrando em Direito do Programa de Pós-Graduação em Direito da Universidade Federal de Pelotas. Graduado em Direito pela Universidade Federal de Pelotas. Advogado.
} 
arises as a counterargument to the egalitarian liberalism and to the libertarianism, helping to understand and justify the new historical and legal circunstances. Therefore, the social and diffused rights find theorical and argumentative support in the work of authors who are in the communitarist spectrum. The present study aims to present a brief introduction to that thought, and,after that, to analyze some examples taken from the constitutional norms to test the hypothesis. The methodology used was the hypothetical-deductive, since it was based on the hypothesis of the communitarianist theoretical adequacy in order to deduce its conformation to social and diffuse rights. In terms of research technique we used the bibliographic. On the other hand, in terms of research technique, the work used the bibliographic method.

\section{KEYWORDS:}

Diffused rights, Social Rights, Constitucional Theory, Democracy, Judicial Activity.

\section{INTRODUÇÃO}

No contexto pós-guerra, com o anúncio de direitos fundamentais, especialmente a partir da Declaração dos Direitos do Homem e do Cidadão, o surgimento de direitos até então não previstos nos ordenamentos jurídicos internos - especialmente nos países ocidentais - se tornou uma realidade crescente. Isso deveu-se aos aspectos históricos, sociais, políticos, econômicos e jurídicos (características factuais) que estimularam a mudança de paradigmas de compreensão da sociedade, do Estado e da justiça (características teóricas), especialmente aquelas surgidas na segunda metade do Século XX e até aqui no Século XXI.

Dentre as mudanças de perspectiva teórica, destaca-se a mitigação do paradigma liberal clássico, com a consolidação de uma ética voltada à equidade e à coletividade, características próprias da segunda e da terceira dimensões dos direitos fundamentais. Isso deve-se à contribuição do movimento denominado "liberalismo igualitário" (Ronald Dworkin, John Rawls, dentre outros) e, sobretudo, pelos autores do chamado "comunitarismo" (Michael Sandel, Charles Taylor, Michael Walzer, Alasdair Mcintyre, dentre outros).

Destarte, o presente artigo pretende estabelecer uma revisão resumida do pensamento comunitarista e, com o intuito de colocar à prova a hipótese de que referida corrente teórica fundamenta os direitos sociais e os direitos difusos, apresentar alguns exemplos extraídos das normas constitucionais, considerando-se que estabelecer a relação entre a teoria e os 
dispositivos normativos constitucionais contribui na compreensão dos objetivos e na aplicação práticas dos mesmos.

\section{UMA BRAVE INCURSÃO NA EVOLUÇÃO DO ESTADO E DOS DIREITOS FUNDAMENTAIS}

A Constituição deixou de ser considerada uma "Carta de intenções" políticas do Estado e passou a ser tratada como documento normativo, cuja força jurídica se assenta em uma hierarquia vinculante de sua interpretação. Destarte, exige-se a concretização das normas constitucionais, e, para isso, deve-se levar em consideração a unidade da constituição, a sua concordância prática, a sua força normativa, a sua "justeza funcional" e sua condição histórica (HESSE, 1993, p. 26-28). Por conseguinte, a densidade e o desenvolvimento de teorias que impõe a aplicação das normas de direitos fundamentais passaram a ser elemento de destaque na teoria do direito constitucional.

Essa nova perspectiva de força normativa das normas constitucionais deve-se à passagem do Estado liberal ao Estado social. O Estado liberal, guiado pelo liberalismo político, foi empregado como estrutura ideológica que combatia o absolutismo monárquico. Isso significou, a partir do século XVII, a afirmação dos princípios basilares da vida política com a defesa dos direitos políticos do indivíduo, dos direitos de expressão, de associação e de propriedade (DORTIER, 2010, p. 361).

Nas palavras de Japiassu e Marcondes (2001, p. 119), o Liberalismo político elege a "vontade individual como fundamento das relações sociais, defendendo, portanto, as liberdades individuais - liberdade de pensamento e de opinião, liberdade de culto etc. — em relação ao poder do Estado, que deve ser limitado". Assim, postulou-se o pluralismo das opiniões e a independência entre os poderes que constituem o Estado. Nesse sentido, a atividade estatal abrangeria um espectro reduzido e previamente reconhecido de atuação, como, por exemplo, a manutenção da ordem e da segurança, inclusive por meio da função judicante imparcial (concepção clássica de jurisdição). 
Ocorre que, por motivos diversos e complexamente interligados, a atuação Estatal passa a ganhar status de positividade, os problemas sociais latentes em relação à supressão da liberdade formal por meio da supressão da personalidade. Com isso exigiu-se do liberalismo burguês a necessidade de correção conceitual da liberdade, no sentido de se estabelecer direitos e garantias de teor material da liberdade. Trata-se do reconhecimento das conquistas sociais e econômicas orientadas para garantirem o conceito formal de liberdade (BONAVIDES, 2007, p. 59).

A propósito da transmutação do modelo de Estado Liberal para o modelo de Estado Social, destaca-se que

no campo das liberdades, já nas décadas finais do século XIX, um novo componente emerge, a justiça social, e reivindicações igualitárias transformam a sua face, dando início à construção do que irá se tornar o Estado Social e suas diversas expressões ao longo do século XX e a consolidação das chamadas liberdades do ou da - as liberdades positivas (STRECK e MORAIS, 2006, p. 65).

Pode se afirmar que, em termos de matrizes filosóficas a ampararem a perspectiva liberal, a ideia de contratualismo e liberdade possuem forte carga da concepção idealista de mundo, até mesmo por se reportar a pré-existência de valores absolutos e condições sine qua non de convívio social - como por exemplo a própria liberdade. Todavia, o liberalismo, ao menos em sua concepção clássica, não aparentava capacidade de lidar com um aspecto introduzido pela filosófica política: a ideia de justiça social.

Tal "paradigma teórico", somado ao aumento das reivindicações sociais e ao contexto histórico do período denominado "pós-guerra", tornou o ambiente propício ao surgimento e inauguração da fase do Estado Social (Welfare State). Esse modelo de Estado, por sua vez, pode ser caracterizado como aquele que "garante tipos mínimos de renda, alimentação, saúde, habitação, educação, assegurando-os a todo cidadão, não como caridade, mas como direito político" (BOBBIO apud. STRECK e MORAIS, 2006, p. 79).

Desta forma, não é incorreto afirmar que considerável fração de direitos sociais atualmente preconizada no ordenamento jurídico brasileiro advém desse período e está assentada na ideia de que o Estado, em dado momento e em dadas circunstâncias, deve intervir para proteger a dignidade humana e realizar, em determinado nível, o predicado da igualdade material. Trata-se de uma perspectiva fortemente fundamentada no paradigma materialista de 
compreensão do mundo, haja vista o "aqui" e o "concreto" ganharam espaço e relevância, em detrimento de aspectos teóricos metafísicos, ontológicos ou ideais.

Ocorre que, dadas as experiências históricas, não se pode negar que em boa parte das tentativas de concretização do Estado Social - especialmente por meio da implantação de regimes socialistas - acabou por derrocar em regimes autoritários, os quais, sob o pretexto de garantirem a (suposta) igualdade material, ensejaram o desrespeito às liberdades e garantias individuais em suas mais variadas vertentes. Por tal motivo, e dada a evolução histórica e teórica do pensamento político-jurídico, estamos diante daquilo comumente denominado como Estado Social e Democrático de Direito - compreendido como um Estado que promove a justiça social mediante os procedimentos e limites do Estado Democrático de Direito (SARLET, 2015, p. 463).

No caso específico do Brasil, que por meio da Magna Carta apresentou um projeto de Estado claramente pré-definido, por meio de um Constitucionalismo Dirigente, dotado de valores, princípios e normas que devem ser obedecidos, prestigiados e efetivados, sob pena de ruptura e/ou colapso da ordem constitucional, esse cenário de crise fica ainda mais em evidência. Diferente da Grundgesetz (Art. 20, Abs. 1) (BADURA, 1996, p. 256-257), a Constituição Federal do Brasil não possui uma cláusula que estabeleça o Estado social. No entanto, ela prevê diversos direitos sociais (e.g. Art. $6^{\circ}$ da $\mathrm{CF}$ ) e determina a sua aplicação imediata (Art. $5^{\circ}, \S 1^{\circ}$, da CF).

Giza-se ainda que, na (já) clássica doutrina do direito constitucional brasileiro, é comum que os direitos fundamentais sejam apresentados a partir de suas gerações - ou dimensões, como preferem alguns -, como uma maneira de exposição e cotejamento analítico que de um lado explique metodologicamente os avanços do ordenamento jurídico constitucional e, do outro, tenha aderência e contextualização histórica com o momento político-social vivido naquela época. Por conseguinte, é oportuno que nesse momento seja ressaltada, ainda que resumidamente, as diversas dimensões dos direitos fundamentais, inclusive porque esse recorte histórico, embora não seja definitivo ou isento de críticas, é indispensável para a análise da hipótese de pesquisa ora suscitada.

A primeira dimensão de direitos fundamentais é aquela trazida pela concepção de Estado Liberal: são direitos de liberdade, também conhecidos como direitos de prestação 
negativa, "caracterizados por um cunho fortemente individualista, concebidos como direitos do indivíduo frente ao Estado, mais especificamente, como direitos de defesa, demarcando uma zona de não intervenção do Estado e uma esfera de autonomia individual em face do seu poder" (SARLET, MARINONI e MITIDIERO, 2014, p. 274): por meio deles, fica socialmente acertado que o soberano estatal não ultrapassará as fronteiras do "privado", não interferirá na liberdade negocial, tampouco limitará a liberdade do pensamento e da crença. É também por meio deles que ganham especial atenção o direito à vida, à liberdade, à propriedade, à igualdade perante a lei, à participação política.

A segunda dimensão de direitos fundamentais é aquela que caracteriza um dever de ação do Estado, característica última do chamado Estado Social, que rompeu com o liberalismo político até então dominante: traz aos indivíduos pretensões jurídicas de exigirem do Estado uma postura proativa na concretização material da igualdade e das condições de vida boa. $\mathrm{O}$ exemplo máximo desta categoria de direitos fundamentais são os próprios direitos sociais, no Brasil previstos nos arts. $6^{\circ}$ e $7^{\circ}$ da Constituição Federal, que apontam a educação, a saúde, a alimentação, o trabalho, a moradia, o transporte, o lazer, a segurança, a previdência social, a proteção à maternidade e à infância e a assistência aos desamparados com o caráter de jusfundamentalidade, "revelando uma transição das liberdades formais abstratas para as liberdades materiais concretas, utilizando-se a formulação preferida na doutrina francesa" (SARLET, MARINONI e MITIDIERO, 2014, p. 275).

A terceira dimensão dos direitos fundamentais, por sua vez, se relaciona à noção de um direito à paz, a uma qualidade de vida saudável, a um meio ambiente equilibrado e à proteção dos consumidores hipervulneráveis na sociedade de massa. Por tais motivos, são corriqueiramente denominados como direitos de fraternidade ou de solidariedade, trazendo como característica diferencial "o fato de se desprenderem, em princípio, da figura do homemindivíduo como seu titular, destinando-se à proteção de grupos humanos (povo, nação), caracterizando-se, consequentemente, como direitos de titularidade transindividual" (SARLET, MARINONI e MITIDIERO, 2014, p. 276).

Prosseguindo-se, embora não unânime, alguns autores mencionam a existência de uma quarta dimensão dos direitos fundamentais, na qual se incluiriam os direitos à democracia, à informação e ao pluralismo (BONAVIDES, 2004, p. 572), e até mesmo uma quinta dimensão, na qual haveria uma normatização do patrimônio genético. Os contrários a essa tese - corrente 
a qual nos filiamos -, por critérios metodológicos, tendem a preferir a inclusão de tais direitos no rol da chamada "3a geração".

Não se pode afirmar de forma absoluta, mas considerando-se que o reconhecimento da

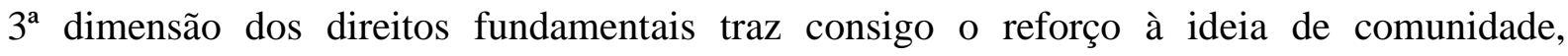
solidariedade e vida social, bem como aparenta reforçar a ideia de compartilhamento e fortalecimento de uma ética pública que volte a visar o bem comum, é possível se inferir que as teorias de justiça havidas desde a metade do século $\mathrm{XX}$ até o presente momento, por mais particulares que sejam entre si, corroboram e servem de suporte teórico a essa alteração paradigmática. É essa a hipótese aqui invocada.

Nesse sentido, tanto a perspectiva do liberalismo igualitário - defendido, dentre outros, por John Rawls -, quanto a perspectiva de democracia pragmática-procedimentalista defendida por Habermas e Rorty, por exemplo - ou, principalmente, a perspectiva da filosofia política comunitarista - sustentada, dentre outros, por Michel Walzer, Charles Taylor e Alasdair Macintyre - parecem corroborar essa inferência. Frisa-se que, com essa afirmação, não se pretende misturar as diferentes correntes ou colocá-las no mesmo nível teórico: são todas sobremaneira diferentes, inclusive por vezes havendo forte crítica de uma para com as outras.

Da leitura contextual do momento teórico contemporâneo, contudo, é possível se depreender que todas elas têm uma característica em comum: o retorno à sociedade civil como meio e fim do agir público (em termos políticos, jurídicos e éticos). Daí porque, salvo melhor juízo, o surgimento de alguns direitos de segunda dimensão, e, principalmente, o advento da terceira dimensão não estaria vinculada a uma forma específica de Estado, mas, sim, a alteração das percepções teóricas e sociais a respeito da vida em sociedade e do bem comum e do papel que o direito pudesse assumir nesse sentido.

\section{O PENSAMENTO COMUNITARISTA}

O significado contemporâneo do termo comunitarismo, conforme destaca João Pedro Schmidt (2011, p. 301) - de pertencente a ou característico de uma comunidade - tornou-se 
popular "tão somente a partir dos anos 1970 com o debate entre liberais e comunitaristas", sendo que o lugar comum remete-nos à obra de alguns autores como Alasdair MacIntyre, Michael Walzer, Michael Sandel e Charles Taylor. É evidente que existem diferenças inegáveis entre a obra desses autores, motivo pelo qual as mesmas não podem ser compreendidas como idênticas. Ademais, poderia se cogitar de uma utilização diversa do tema - que fugisse, portanto, do lugar comum dado à expressão "comunitarismo". No entanto, por critério metodológico, será justamente esse "lugar comum" o recorte teórico escolhido.

Os comunitaristas enfatizam a importância das instituições sociais no desenvolvimento do significado individual e da identidade, numa constante retomada da ética coletiva em detrimento de aspectos ou fundamentos exclusivamente individualistas. Schmidt (2011, p. 302), citando o pensamento de Etzioni, define o comunitarismo como "o pensamento que se preocupa fundamentalmente com a comunidade - e não com o Estado ou o mercado. $\mathrm{Ou}$, em outras palavras, o pensamento que confere destaque à comunidade na construção da boa sociedade".

Ainda, o autor aponta os debates teóricos travados nas décadas de 1980 e 1990 com pensadores de vertente liberal (principalmente o liberalismo igualitário, e, em certa medida, o libertarianismo) - no sentido de que "o liberalismo não leva em conta suficientemente a importância da comunidade para a identidade pessoal, o pensamento moral e político e os julgamentos acerca de nosso bem-estar no mundo contemporâneo" (BELL, 1993 apud. SCHMIDT, 2011, p. 307).

Numa breve síntese, podem ser indicados como principais características do Comunitarismo os seguintes pressupostos teóricos: (a) a Comunidade é condição ontológica do ser humano; (b) a necessidade de uma oposição ao individualismo e ao coletivismo; (c) a necessidade de uma oposição ao gigantismo e ao centralismo estatal; (d) a primazia dos valores pessoais sobre os valores de mercado; (e) a valorização da subsidiariedade, do poder local, da cooperação, do associativismo e da autogestão; e (f) a reafirmação dos princípios da fraternidade, igualdade e liberdade (SCHMIDT, 2011, p. 308-311).

Do denominado movimento comunitarista, para a finalidade que se propõe o presente trabalho, o primeiro pensador a ser destacado é o norte-americano Michael Sandel, autor, dentre outras obras, de "Justiça: O que é fazer a coisa certa" e "Liberalismo e os limites da Justiça". 
Protagonista de vários debates travados em face das proposições do liberalismo igualitário, merece destaque a crítica levada a efeito por Sandel no sentido de que, dada a nossa natureza, torna-se impossível adotarmos completamente o véu de ignorância proposto por Rawls. Nesse sentido, questiona se "a experiência hipotética de Rawls é a maneira correta de abordar a questão da justiça?” (SANDEL, 2012, p. 179).

Com efeito, para Sandel,

\begin{abstract}
Embora Rawls admita a intersubjetividade do eu, ele carece da concepção de u eu racional e unificado que fundamente sua tese da prioridade do direito sobre o bem. Além disso, o liberalismo deontológico de Rawls requer uma concepção de justiça que não pressuponha nenhuma concepção particular do bem, para servir de estrutura no interior da qual diferentes concepções do bem se tornem possíveis. O primado da justiça é ao mesmo tempo uma prioridade moral e uma forma privilegiada de justificação. O justo é visto como anterior ao bem não só porque suas exigências têm precedência natural, mas também porque seus princípios são produzidos de modo nãoconsequente, como se racionalmente derivados das condições da posição original. Contudo, para que realmente admitamos que podemos aceitar o resultado, isto é, os princípios de justiça derivados das estimativas da posição original, é necessário aceitar que o sujeito (o eu racional que toma decisões) existe independentemente de suas intenções e seus fins. Rawls exige a aceitação de um sujeito que possa ter uma identidade definida antes dos valores que ele possa escolher (MORRISON, 2006, p. 486).
\end{abstract}

A crítica invoca uma aparente incoerência havida no interior da teoria rawlsiana: Rawls, ao limitar a ideia de comunidade enquanto resultado da soma cooperativa dos interesses individuais previamente conhecidos, por intermédio do princípio de diferença (de índole de participação), aparentemente torna-se exigível a existência de um vínculo moral preexistente "entre aqueles que vão distribuir os bens sociais, e, portanto de uma comunidade constitutiva cujo reconhecimento requer" (MORRISON, 2006, p. 486).

É importante salientar, inclusive, que a obra "Liberalismo e os limites da Justiça" foi conhecida por Rawls, de modo que a crítica lá desenvolvida foi uma das razões que fez Rawls declarar posteriormente que sua teoria não era metafísica, mas uma teoria política, num sentido de que um consenso poderia ser formado mesmo com vários indivíduos com morais e políticas diversas. Tal ideia é exposta no artigo Justiça como equidade: uma concepção política, não metafísica (RAWLS, 1992).

É nesse contexto que Sandel (2012, p. 179) questiona se “a experiência hipotética de Rawls é a maneira correta de abordar a questão da justiça?", igualmente perguntando "como podem princípios de justiça resultar de um acordo que jamais aconteceu de fato"? (SANDEL, 
2012, p. 179). De modo a analisar criticamente a ideia de Rawls, Sandel tenta ilustrá-la a partir da imagem de um contrato perfeito. Assim, inicialmente pondera que um contrato tem sua força decorrente da autonomia e reciprocidade (SANDEL, 2012, p. 187), sendo que, não obstante possa haver um acordo, a consensualidade por si só não garante que este seja justo, já que as partes contratantes podem estar em situações de barganha e conhecimento distintos (HERRERA GÓMEZ, 2007, p. 155-157).

A partir disso, Sandel passa a imaginar um contrato em que as partes estão em situação igual, e estão tentando definir os princípios que governam a vida das pessoas em geral. E certo é que, em um cenário como esse, não haveria margem para coerção, engano ou outras vantagens injustas. É a partir daí - e somente em um cenário como este - que Sandel admite que terá sido compreendida "a concepção de Rawls de acordo hipotético baseado na equanimidade. $O$ 'véu de ignorância' garante a equanimidade do poder e do conhecimento que a posição original requer" (SANDEL, 2012, p. 188).

Prosseguindo sua abordagem crítica à obra rawlsiana, Sandel destaca que as pessoas escolheriam os princípios da liberdade e da igualdade para evitar serem vítimas de opressões ou ficarem em uma tamanha situação de desigualdade que as impossibilitaria de progredir socialmente. No entanto, após analisar a sociedade de mercado e a concepção meritocrática, o autor pondera que "alguns críticos da teoria igualitária acreditam que a única alternativa para uma sociedade de mercado meritocrática seria uma igualdade niveladora que impusesse limitações aos indivíduos com mais aptidões” (SANDEL, 2012, p. 193).

E daí se extrai justamente uma das características do comunitarismo: a partir do reconhecimento das diferenças entre os indivíduos, por um lado, e da necessidade de reequilíbrio de condições iniciais mínimas, do outro, é que o comunitarismo (enquanto teoria crítica ao liberalismo-igualitário), entende justificável e desejável, a partir da adoção de uma ética pública da alteridade, a criação/estímulo de incentivos reequilibradores do pacto social em uma dada comunidade. Nesse sentido, estaria se afastando do conservadorismo dos liberais ao considerarem a necessidade de existência princípios superiores que deveriam reger a ordem social e a sociedade, em detrimento do reconhecimento da convivência de pessoas de diversas culturas, religiões e/ou etnias (HERRERA GÓMEZ, 2007, p. 157).

Outro pensador de enorme relevo ao pensamento contemporâneo é Charles Taylor. 
Desenvolvedor de um ponto de vista comunitarista, Taylor reconhece que os indivíduos são integrados por contextos culturais e sociais e, justamente por isso, torna-se crítico do empobrecimento de qualquer mundividência cultural que pregue a existência de uma suposta natureza autossuficiente do indivíduo (MORRISON, 2006, p. 487).

Com efeito, segundo Taylor, uma racionalidade coerente e apta a permitir que o homem atue como sujeito moral capaz de descobrir o bem, o justo e o injusto somente pode ser descoberta a partir da participação numa comunidade de linguagem e discurso mútuos sobre o justo e o injusto, o bem e o mal (MORRISON, 2006, p. 487-488).

Ocorre que, para o autor, os paradigmas teóricos da modernidade teriam acentuado o individualismo e o pessimismo/desencanto do mundo. Isso porque, a partir do momento em que a sociedade não seria possuidora de uma estrutura estável de comunidade - como pretende alguns dos pensadores da chamada modernidade tardia -, os arranjos sociais estariam constante e completamente disponíveis à redefinição, o que viria a tornar, como únicas metas possíveis a serem alcançadas, a felicidade do indivíduo e o bem-estar decorrente de sua autorrealização.

Para Taylor, "esse indivíduo moderno (...) é resultado de um longo e complexo desenvolvimento histórico, e é somente num certo tipo de sociedade que se torna possível a existência de tal indivíduo livre, capaz de escolher seus próprios objetivos" (MORRISON, 2006, p. 488).

É nesse cenário argumentativo que Taylor desenvolve os conceito de Self pontual e razão desengajada (TAYLOR, 2000): um self que "instrumentaliza seus desejos, inclinações, tendências, hábitos de pensamento e sentimentos, de modo a reforçar aqui, demolir ali, construindo a pessoa que quer ser" (OLIVEIRA, 2006, p. 138), sendo esta uma das fontes do próprio mal-estar contemporâneo, haja vista a absoluta impossibilidade de colocar tal raciocínio em prática, considerando que as formas de individualismo implicariam não apenas na questão da liberdade individual, mas, em última análise no próprio modelo de arranjo social (OLIVEIRA, 2006, p. 138).

Daí porque a acusação central tayloriana à tradição liberal é de que a mesma aparentaria total "ignorância da verdadeira história e da realização social, o hábito de tratar como natural 
aquilo que é, na verdade, uma tênue criação social-humana e, consequentemente, enfraquecer o imperativo político de participação da criação da modernidade" (MORRISON, 2006, p. 488).

Esse caminho de preponderância absoluta do individual sobre o coletivo, denuncia Taylor, tende a impor um atomismo social, com o intuito de "ver a realização apenas como do self, negligenciando ou deslegitimando as demandas que vêm de fora de nossos próprios desejos ou ambições, sejam elas da história, da tradição, da sociedade, da natureza ou de Deus" (TAYLOR, 2011, p. 66).

Para Taylor, o ideal de autenticidade

\begin{abstract}
só será plenamente realizado se orientado por determinados parâmetros objetivos, externos ao sujeito, que servem de critério para a valoração das ações individuais. Dessa forma, a autenticidade é reforçada pelo diálogo, por um reconhecimento social. O indivíduo só será capaz de formar sua identidade através diálogos com outros indivíduos e com os elementos da ordem normativa da sociedade na qual está inserido. A identidade, portanto, envolve não apenas a criação e a originalidade de cada indivíduo, sendo diretamente influenciada pelo diálogo de uma determinada comunidade, que fornece os horizontes de sentido e uma ética para a delimitação dos processos de identificação das pessoas e dos agrupamentos sociais (SILVEIRA, ROCHA e CARDOSO, 2012, p. 32)
\end{abstract}

Noutras palavras, a própria ideia de que cada indivíduo possui suas particularidades, racionalidade e seus planos de vida, "só está disponível num certo tipo de sociedade, portadora de uma determinada cultura, em que as pessoas sejam capazes de atribuir alguma significação pertinente" (GUALDA, 2009, p. 23) às próprias concepções.

O terceiro autor cujo pensamento é relevante às pretensões do presente trabalho é o pensador norte-americano Michael Walzer, cuja obra de maior destaque é As esferas da justiça.

Sendo a desigualdade um dos pilares da teoria de Walzer, a crítica feita pelo autor ao liberalismo justamente parte da ideia de que o mesmo desconsidera a desigualdade, deixando de "reconhecer a devida importância às associações involuntárias que, marcadas pela desigualdade, seriam as principais protagonistas da política multicultural" (SANTOS NETO e HEINEN, 2012, p. 288).

Como consequência teórica dessa crítica, Walzer sustenta que o liberalismo é uma prática política defeituosa e inapta à boa pacificação social, haja vista que, nas discussões e deliberações por ele fomentadas, os debatedores praticamente jamais abordam a experiência concreta da desigualdade ou a luta contra ela: simplesmente adota-se uma neutralidade, 
caracterizada pela negativa e/ou desconsideração da (inevitável) desigualdade. Nesse contexto, a proposta de Walzer é produzir um liberalismo por meio da correção comunitarista, "que esteja mais ao alcance da apropriação e utilização igualitárias", sendo que sua proposta pretende ser capaz de abranger, explicar e embasar a mobilização democrática e a solidariedade (WALZER, 2008 apud. SANTOS NETO e HEINEN, 2012, p. 289).

Em Esferas da Justiça, Walzer rechaça a busca por um princípio universal de justiça e sustenta a justiça como criação de uma comunidade política determinada, em um momento determinado, sendo que a interpretação deve ocorrer a partir da própria comunidade (SANTOS NETO e HEINEN, 2012, p. 289).

O último autor escolhido para a presente abordagem é o filósofo britânico Alisdair MacIntyre, cujas obras mais aclamadas são "Depois da Virtude" e "Justiça de quem? Qual racionalidade?"

Seguindo a linha crítica ao liberalismo igualitário e ao libertarianismo, para o autor, "tanto Rawls quanto Nozick ignoram o que, no seu entender, deveria ser fundamental para a justiça: a ideia de virtude" (MORRISON, 2006, p. 488) - conceito chave na obra do autor.

Para o autor, a modernidade teria deslocado a linguagem da moralidade. Nesse sentido, seguindo sua linha de raciocínio, em verdade estaríamos cercados por discursos de moralidade, e nossa moralidade moderna teria se tornado mera emotividade, "nada além de expressões de preferências subjetivas" (MORRISON, 2006, p. 488).

Tal circunstância, somado ao fato de que as "teorias modernas só conseguem conceber a sociedade como se esta fosse formada por indivíduos cujos interesses são definidos antes, e independentemente, da construção de qualquer vínculo moral ou social entre eles" (MORRISON, 2006, p. 489), levariam à inevitável conclusão de que as teorias morais toraramse mera apologia ao individualismo, ao ponto de "ser visto como a fonte do niilismo que lentamente vem destruindo nossas sociedades" (MORRISON, 2006, p. 489).

Para o autor, "a ética é uma ética teleológica, profundamente preocupada com a vida boa e com o Bem" (CAMPELO, 2014, p. 6). Sem deixar de ser, ainda, "uma ética racionalista que não se distancia do processo de criação das emoções e dos afetos e da dependência das circunstâncias e dos contextos culturais e sociais" (CAMPELO, 2014, p.6). 
Mantendo a noção de "virtude" como ponto central de sua obra, MacIntyre, recorre à ideia de tradição como forma de adoção de um padrão distinto das organizações sociais da comunidade.

Nesse sentido, "as virtudes devem ser integradas aos padrões gerais de uma tradução informada pela busca do bem e do melhor" (MORRISON, 2006, p. 490), sendo que a virtude não seria "apenas um problema para o indivíduo; a concepção de virtude requer uma tradição que tenha acumulado alguma experiência sobre os bens intrínsecos às práticas" (MORRISON, 2006, p. 490).

Como alternativa para a realização da ética e da justiça, MacIntyre defende como alternativa o resgate da tradição da virtude. Com efeito,

\footnotetext{
o contexto de justiça deve ser o de uma comunidade, que em seus valores, práticas e instituições amadurecidos historicamente formam um horizonte normativo que é constitutivo para a unidade de seus membros e para as normas do justo. Os princípios de justiça resultam de um dado contexto comunitário, valem somente nele e somente ali podem ser realizados. Todas as tentativas de fundamentação de normas fundadas na prioridade dos direitos individuais ou dos procedimentos formais permanecem estranhas a este contexto (CAMPELO, 2014, p. 9).
}

A consciência moral do indivíduo seria consequência do reconhecimento da dependência do indivíduo, conduzida pela vivência das virtudes, e valorizaria um ambiente aonde deveres e direitos individuais se aliariam com aquilo que é comum a todos, sendo trabalhados em forma de reciprocidade. Isso porque, "o conhecimento de si mesmo, bem como o conhecimento da realidade na qual o indivíduo está inserido, acontece por meio da rede de relações e situações com os diferentes membros da sociedade" (ROSA, 2016, p. 42).

Dessa brevíssima síntese do pensamento dos autores nominados comunitaristas, e conforme já dito anteriormente, percebe-se que existem inúmeras divergências entre estes pensadores, motivo pelo qual suas teorias não devem ser encaradas, indistintamente, como idênticas.

No entanto, há evidentes traços em comum, que servem para classificá-los como pertencentes ao mesmo movimento teórico - e, por conseguinte, para utilizá-los como o mesmo referencial teórico no presente trabalho. E uma dessas características, sem sombra de dúvidas, é corresponde às críticas emanadas contra o liberalismo igualitário e o libertarianismo (esses 
últimos também chamados de liberistas). E acerca dessas críticas, como forma de sintetizar aquilo até aqui exposto, mostram-se oportunas as palavras de José Reinaldo de Lima Lopes:

\begin{abstract}
Em resumo, pode-se dizer que os liberais e liberistas compartilham um fundamento essencial que é a procedência da liberdade e da autonomia na reflexão ética. Há entre eles, porém, a distinção importante: para os liberais, na ética pública, isto é, na política, a autonomia se exerce dentro de um quadro de solidariedade mínimo que determina e define por princípio, as liberdades. Havendo uma esfera autônoma de nãointervenção do estado e da sociedade sobre a vida privada, há também um limite para o sujeito, que consiste no princípio da diferença socio-econômica: esta só é justicável se não piora a sorte dos menos favorecidos (ex.:John Rawls, Ronald Dworkin (EUA), Alexy (Alemanha). Para os liberistas, qualquer preocupação como o resultado dos processos de intervenção entre agentes livres é injustificável. Pertencem a esta corrente Friederich Hayek e Robert Nozick. Os comunitaristas, por sua vez, reafirmam uma visão organicista da sociedade e a precedência do todo sobre as partes, ou seja, da comunidade sobre o indivíduo. (LOPES, 1996, p. 31)
\end{abstract}

Não por outra razão, parece adequada a afirmação de que a crítica comunitarista ao liberalismo pretende ataca-lo em dois aspectos: (i) âmbito metodológico, no sentido de que as teorias liberais deixam de considerar a indissociável inserção dos indivíduos em circunstâncias fáticas e sociais específicas, incorrendo na inegável (e indesejada) adoção de um pressuposto metodológico atomista; e (ii) no âmbito normativo, no sentido de que o liberalismo, ao propiciar um ambiente de exacerbado individualismo moral, "contribuiria para criar uma sociedade fragmentada, indiferente e instrumental" (GUALDA, 2009, p.16), deixando dos aspectos relacionados aos deveres de lado, em benefício apenas e tão somente dos direitos e prerrogativas individuais.

Com efeito, para os comunitaristas, "o indivíduo não seria o único, nem sequer o mais apropriado critério, para justificar o arranjo político, derivar princípios de justiça e delinear uma comunidade política boa e estável" (GUALDA, 2009, p. 17)

Por mais sofisticadas que possam ser as teorias do liberalismo igualitário e do libertarianismo, parece-nos que nenhuma delas consegue responder, satisfatoriamente, algumas das necessidades e controvérsias sociais que têm aparecido ao longo das últimas décadas.

E isso se deve, ao que tudo indica com acerto à crítica comunitarista, que aquelas teorias deixam de levar em conta a complexidade social e as mútuas relações de causa e efeito existentes na equação "coletivo-individual” e "nós-eu" - que correspondem, justamente, ao cenário de onde emergem os avanços quanto aos direitos sociais e difusos. 


\section{A JUSTIFICAÇÃO TEÓRICA DOS DIREITOS SOCIAIS E FUNDAMENTAIS A PARTIR DE ARGUMENTOS COMUNITARISTAS}

Agora, a partir da reflexão sobre a normatividade constitucional, buscar-se-á uma análise do ordenamento jurídico de modo a se refletir se os argumentos comunitaristas podem ser considerados como fundamentos justificantes dos direitos sociais e difusos - ou não.

Adentrando-se na reflexão, destaca-se o trabalho de Santos Neto e Heinen (2012), ao, a partir do modelo proposto por Michael Walzer em As esferas de Justiça, fazerem uma análise dos critérios de distribuição de bens sociais na jurisprudência do Superior Tribunal de Justiça (STJ), tendo sido abordados os seguintes bens sociais: pertencimento, segurança, saúde, bemestar, educação e cargos públicos.

Quanto ao bem social "pertencimento", a partir da ideia walzeriana de que pertencer a uma comunidade humana seria um bem primário - haja vista que, quem não pertence a nenhuma comunidade estaria alheio a todos os bens coletivamente distribuídos (SANTOS NETO e HEINEN, 2012, p. 292). E forma como referido bem seria tutelado no ordenamento jurídico, segundo os autores, seria, para além da previsão legal, no Estatuto do Estrangeiro, quanto à possibilidade de tornar-se brasileiro naturalizado, a própria hermenêutica jurídica, a partir de um viés ampliativo/concretizador, por meio da qual seria viável a mitigação dos requisitos legais no caso concreto, quando houvesse conflito de valores de dimensões distintas.

Já no que tange à segurança, saúde e bem-estar, a partir da concepção walzeriana de que "não há superávit real algum em um Estado enquanto as necessidades não tenham sido satisfeitas, pois se trata do primeiro encargo contra o produto social" (SANTOS NETO e HEINEN, 2012, p. 294), bem como considerando a ideia de ser necessário que o conteúdo de preenchimento de tais bens deve ser definido em conformidade com a cultura de um povo, após a participação ativa dos cidadãos neste debate, seria viável a atuação judicial (judicialização das políticas públicas) para a garantia de sua concretização.

O terceiro bem abordado pelos autores, a educação, recebe especial atenção por Walzer, haja vista constituir um conjunto específico de bens sociais que "oferecem um contexto, não o único, porém o mais importante, para o desenvolvimento do entendimento crítico e para a 
produção, bem como a reprodução de críticos sociais” (WALZER, 2003, p. 270). No entanto, é justamente por meio da análise deste bem social que o pensamento de Walzer ganha distância considerável da realidade prática brasileira. Isso porque Walzer (i) rechaça o critério "capacidade", consagrado na legislação brasileira, sob o argumento de que ninguém teria, somente por ser capaz, direito a receber uma educação especializada (nível superior), e que é a comunidade que devem decidir quais tipos de profissionais especializados necessita e como distribuirá as vagas dos cursos para capacitação; e (ii) discorda frontalmente da adoção de um sistema de cotas, sustentando que tal viola os direitos dos candidatos (SANTOS NETO e HEINEN, 2012, p. 297-298).

Por mais óbvio que possa parecer, a propósito destes pontos sustentados por Walzer, mostra-se oportuno destacar que os mesmos não representam o comunitarismo como um todo ${ }^{3}$, mas, tão somente, a sua própria argumentação. Michael Sandel, outro autor tido por comunitarista e já abordado acima, é um pensador que defende a máxima universalização possível do direito à educação - dando-se a todos eventuais interessados o direito de acesso à educação -, bem como entende medida de justiça reparatória a adoção de sistema de cotas como forma de promover o acesso à educação (SANDEL, 2012, p. 225-226).

Por tal motivo, e aproximando-se mais do pensamento de Sandel, entende-se que tanto a universalização da educação, quanto o acesso à educação por meio de cotas - ambas legalmente previstas no ordenamento jurídico brasileiro - correspondem a direitos justificados sob argumentos da teoria comunitarista. Outro bem social concerne ao acesso aos cargos públicos. Para ele, “os cargos públicos devem ser distribuídos por critérios públicos conhecidos e procedimentos transparentes, tendo em vista que o seu alcance constitui uma vantagem econômica e estatal" (SANTOS NETO e HEINEN, 2012, p. 299), sendo a perfeita meritocracia a meta na distribuição dos cargos públicos.

A meritocracia, contudo, não se limitaria à análise estrita dos indivíduos mais bem qualificados, porque a qualificação seria um dos casos especiais de merecimento, porém não o

\footnotetext{
${ }^{3}$ Isso porque, como já dito anteriormente, o comunitarismo não se trata de uma teoria fechada e absolutamente homogênea, mas, sim, um movimento teórico formado por pensadores que possuem em comum as críticas ao liberalismo e libertarianismo.
} 
único, haja vista que podem haver inúmeros candidatos com iguais qualificações para determinado cargo, sendo necessária a adoção do critério do merecimento.

Ainda quanto ao preenchimento dos cargos, para Walzer "a vedação ao nepotismo tem como um de seus propósitos assegurar que a carreira esteja aberta ao talento, bem como os direitos de candidatura a todo cidadão" (SANTOS NETO e HEINEN, 2012, p. 300), sendo que, nesse contexto, nem o pertencimento ao grupo, tampouco o parentesco, podem contar como qualificação ou merecimento. No Brasil, tanto a exigência constitucional de realização de concurso público para o ingresso em cargo público efetivo, quanto a absoluta vedação ao nepotismo, são exemplos normativos que dialogam com a perspectiva walzeriana, num sentido estrito, e com o comunitarismo, num sentido mais ampliado.

Outros exemplos que podem ser encontrados na Carta Constitucional são a previdência social e a assistência social, ambos direitos sociais fundamentais esculpidos no art. $6^{\circ}$ da CF. Quanto a previdência social, a sua normatividade possui um caráter notadamente antiindividualista (o que dialoga com o pensamento defendido pelos comunitaristas, portanto), no sentido de que (i) a contribuição ao sistema previdenciário não é facultativa, mas obrigatória, para todos aqueles que exercem atividade remunerada, justamente para viabilizar o financiamento e o equilíbrio notarial do regime previdenciário, e, assim, fazendo prevalecer a supremacia do "todo" em relação ao "um"; e (ii) a concessão dos benefícios previdenciários, em regra, dependem da realização das contribuições, fazendo-se valer o princípio da solidariedade contributiva (só posso gozar de benefícios que eu ajudei a concretizar).

Já quanto à assistência social (ou "assistência aos desamparados", nos dizeres da Constituição Federal), argumentos comunitaristas podem ser utilizados na justificativa de que, mesmo que não seja justo que alguém que não contribuiu e não possui qualquer mérito para receber dado benefício, o receba gratuitamente, haja vista que, neste caso, o bem e a virtude exercidos coletivamente em situações extremas, se sobrepõe ao critério usual de justo/injusto.

Quando se analisa os direitos difusos, uma aproximação ainda maior fica evidenciada. É o que se observa, por exemplo, do direito fundamental ao meio ambiente equilibrado: nem mesmo o direito de propriedade (que é igualmente fundamental), que de caráter preponderantemente individual, é absoluto em relação à proteção do meio ambiente, que é de caráter coletivo/difuso, havendo previsão constitucional de que a propriedade, para atender a 
sua função social, deve, por exemplo, utilizar de maneira adequada os recursos naturais disponíveis, bem como realizar a preservação do meio ambiente (art. 186, II, CF).

Outros direitos doutrinariamente apresentados como difusos, como a proteção da comunidade indígena, a proteção da criança e do adolescente e a proteção das pessoas portadoras de deficiência, são marcos normativos claramente influenciados pela cosmovisão comunitarista e pelas contribuições teóricas de seus autores.

Ainda que de forma normativa/cogente, a previsão constitucional desses direitos difusos serve à mitigação de ideias individualistas, ao reconhecer, pela via reflexa, que não há como se aceitar um discurso que pregue a natureza de total autossuficiência do indivíduo: apenas a participação numa comunidade - com a possibilidade de aproximação pela linguagem e reconhecimento - é que viabiliza a descoberta e compreensão do justo e do injusto, do bem e do mal, sendo que a partir daí gerada a aptidão do indivíduo a racional e coerentemente buscar agir de tal forma.

Como aponta Ximenes (2010b, p. 122), “enquanto o pensamento liberal interpreta o pluralismo a partir do indivíduo, o comunitarista insiste na primazia das identidades sociais". Assim, a questão que exsurge e ilustra esse argumento comunitarista é sintetizada em como compreender o dever jurídico e moral de proteger os vulneráveis, sem que haja um nível relacional suficiente a enxergá-los?

Quanto à comunidade indígena, a Constituição Federal (BRASIL, 1988) traz especial proteção em seus arts. 231 e 232, reconhecendo a organização social, os costumes, línguas, crenças e tradições, bem como os direitos originários sobre as terras tradicionalmente ocupadas - inclusive com o dever jurídico de demarcação, atribuído à União.

Acerca de tais dispositivos legais, o Supremo Tribunal Federal, no julgamento da PET 3.388/RR (BRASIL, 2009) já se posicionou, inclusive, no sentido de que os mesmos detém "finalidade nitidamente fraternal ou solidária, própria de uma quadra constitucional que se volta para a efetivação de um novo tipo de igualdade: a igualdade civil-moral de minorias, tendo em vista o proto-valor da integração comunitária" (BRASIL, 2009, p. 06), o que se revelaria adequado à aspiração constitucional da efetivação da igualdade civil-moral de minorias e 
justificaria, em termos de constitucionalidade, as ações afirmativas compensatórias pelas desvantagens historicamente acumuladas (BRASIL, 2009, p. 07).

Ao menos parcialmente, depreende-se que a perspectiva comunitarista foi adotada nas razões de decidir daquele julgamento, haja vista a linha de argumentação evidenciada na própria ementa do acórdão, ao afirmar que "no caso, os índios a desfrutar de um espaço fundiário que lhes assegure meios dignos de subsistência econômica para mais eficazmente poderem preservar sua identidade somática, linguística e cultural” (BRASIL, 2009, p. 07), e que tal a aculturação tratada pela Constituição Federal não seria a perda de uma identidade étnica, mas, sim, um somatório de mundividências.

Ou seja: "uma soma, e não uma subtração. Ganho, e não perda. Relações interétnicas de mútuo proveito, a caracterizar ganhos culturais incessantemente cumulativos. Concretização constitucional do valor da inclusão comunitária pela via da identidade étnica” (BRASIL, 2009, p. 07).

Quanto à proteção à criança e ao adolescente, a mesma é preconizada no art. 227, CF, que estabelece como dever "da família, da sociedade e do Estado, a garantia à criança e ao adolescente o direito à vida, à saúde, à alimentação, à educação, ao lazer, à profissionalização, à cultura, à dignidade, ao respeito, à liberdade e à convivência familiar e comunitária" (BRASIL, 1988).

O dever jurídico, mas antes de tudo moral, é dividido de forma tripartite entre a família - primeiro vínculo social e psicológico da criança e do adolescente, de onde se espera as contribuições iniciais para a formação do self, do reconhecimento do outro e do florescimento das virtudes -, mas também à própria sociedade - lócus onde a criança e o adolescente, enquanto indivíduos, vão se inserir na coletividade - e ao Estado - ente jurídico e político que detém o poder e o dever de resguardar e promover os direitos fundamentais de seus cidadãos.

A proteção das pessoas com deficiência, por sua vez, foi estabelecida em alguns dispositivos constitucionais esparsos (art. 203, CF, por exemplo), mas, principalmente, introduzida no bloco constitucional pela adesão à Convenção Internacional dos Direitos das Pessoas com Deficiência, e no âmbito infraconstitucional por meio da promulgação do Estatuto da Pessoa com Deficiência (Lei 13.146/2015). 
Reconhecido o direito à igualdade de oportunidades com as demais pessoas e o direito a não sofrer qualquer espécie de discriminação - legalmente conceituada no $\S 1^{\circ}$ do art. $4^{\circ}$ do Lei 13.146/2015 como sendo qualquer forma de "distinção, restrição ou exclusão, por ação ou omissão, que tenha o propósito ou o efeito de prejudicar, impedir, anular o reconhecimento ou o exercício dos direitos e das liberdades fundamentais de pessoa com deficiência" (BRASIL, 2015).

Ainda, há uma perspectiva de prestígio à vontade individual não imposta, ao se estabelecer, no $\S 2^{\circ}$ do art. $4^{\circ}$, que a "a pessoa com deficiência não está obrigada a fruição de benefícios decorrentes de ação afirmativa" (BRASIL, 2015).

Ambos os elementos - a necessidade de reconhecimento, por parte da coletividade, dos indivíduos portadores de deficiência também por essa condição, e a possibilidade do indivíduo não estar condicionado à vontade da maioria, mas, dentro de sua própria subjetividade (self) e espectro de virtudes, poder exercer escolhas cujas consequências lhe atinjam - demonstram a consciência do pluralismo e a preocupação com aspectos não respondidos pelo liberalismo (clássico ou mesmo o igualitário) ou o libertarianismo.

Além dos exemplos acima extraídos, embora seja apenas tangencialmente relacionado ao presente trabalho, vale a referência ao estudo de Julia Ximenes (2010a), no sentido de apontar a influência dos anseios comunitaristas no que concerne à hermenêutica constitucional, ao controle de constitucionalidade e ao controle judicial das políticas públicas - mas não como consequência imediata da adesão teórica, e, sim, como consequência mediata da utilização dos predicados comunitaristas, especialmente a ampliação dos espaços e condições de participação do cidadão e do reconhecimento dos valores constitucionais enquanto bens socialmente eleitos para este nível. Nesse sentido,

Entretanto, para fins da presente análise, o fenômeno da judicialização da política poderá ser apontado como um efeito da vinculação ao movimento comunitarista apenas em seus contornos jurídicos pela Constituição de 1988, ou seja, a partir da importância concedida à participação do cidadão e da existência de valores e princípios constitucionais. Nossa ressalva reside apenas no fato de não utilizar as estatísticas como um elemento único de análise, tendo em vista que o comunitarismo apregoa mais do que "acesso" aos Tribunais Constitucionais, incluindo uma identidade com os ideais, uma noção de "atitude" e não "ativismo" (XIMENES, 2010a, p. 64).

A bandeira propagada pelo comunitarismo, no sentido de encurtar a distância entre o indivíduo e o poder estatal - de modo a evitar que o mesmo deixe de ser responsivo -, serve à 
defesa inconteste "do exercício da diversidade da diversidade mantida por ideais comuns motivadores, os quais redundam em uma participação comprometida” (XIMENES, 2010b, p. 127).

Nesse contexto, não há como se negar a intersecção entre teoria e prática e a relação de profunda influência que os debates travados pelos comunitaristas produziu (e tem produzido) no ordenamento jurídico brasileiro - seja no âmbito da previsão normativa ou no âmbito da interpretação jurídica.

\section{CONCLUSÃO}

Os surgimentos e/ou afirmação de inúmeros direitos - especialmente os sociais e difusos - é fruto de uma equação sobremaneira complexa, decorrente de aspectos históricos, sociais, políticos, econômicos e jurídicos. Mas, também, é fruto da mudança de paradigmas de compreensão da sociedade, do Estado e da justiça (características teóricas), especialmente aquelas surgidas na segunda metade do Séc XX e até aqui no Séc. XXI, dentre as quais procurou-se destacar o movimento comunitarista.

Após uma breve contextualização da teoria comunitarista, lançando-se mão das proposições que a diferenciam de outras correntes que lhe são contemporâneas - a saber, liberalismo igualitário e libertarianismo -, buscou-se apresentar inúmeros direitos constitucionais já consagrados no ordenamento jurídico brasileiro, e que possuem, na sua essência e natureza jurídica, forte justificação teórica em argumentos que se igualam (ou, no mínimo, são compatíveis com) às proposições comunitaristas. Dentre esses, destacam-se o pertencimento, a educação, a previdência social, a assistência social, o meio ambiente equilibrado, a proteção às comunidades indígenas, a proteção à criança e ao adolescente e à proteção às pessoas com deficiência.

Todos esses exemplos tem em comum o fato de possuírem, em sua justificativa, argumentos de tutela da coletividade num sentido mais latente do que da tutela do indivíduo, e que, tanto para sua existência, quanto para a sua eficácia e asseguração, dependem de uma 
postura que assegure uma participação mais ativa dos cidadãos - tanto no que tange às definições dos mesmos enquanto "bens jurídicos socialmente relevantes", como quanto às definições dos critérios para a respectiva distribuição e imputação de responsabilidades.

Nesse contexto, conclui-se que, mesmo que tangencialmente, e não obstante se saiba que a teoria comunitarista não é tão difundida no Brasil se comparadas com as suas contemporâneas, boa parte das suas concepções de justiça e vida boa foram introduzidas no debate jurídico e político, mostrando-se ainda relevante a realização de estudos que busquem essa aproximação como ferramenta de compreensão do direito e da própria realidade social.

\section{REFERÊNCIAS BIBLIOGRÁFICAS}

BADURA, Peter. Staatsrecht. Systematische Erläuterung des Grundgesetzes für die Bundesrepublik Deutschland. 2 Aufl. München: Beck, 1996.

BRASIL. Constituição da República Federativa do Brasil de 1988. Poder Legislativo, Brasília, DF, 05 de outubro de 1988. Disponível em: < http://www.planalto.gov.br/ccivil_03/Constituicao/Constituicao.htm>. Acesso em 22 de mar. 2020, às 15 h20min.

Supremo Tribunal Federal. Petição 3.388 - RR, Rel. Min. Carlos Ayres Britto, julgado em 19 de março de 2009.

BONAVIDES, Paulo. Curso de direito constitucional. 15 ed. São Paulo: Malheiros, 2004.

BONAVIDES, Paulo. Do Estado liberal ao Estado social. 8 ed. São Paulo: Malheiros, 2007.

CAMPELO, Olívia Brandão Melo. A ética e a justiça para Alasdair MacIntyre. Arquivo Jurídico. Teresina, v. 1, n. 6, p. 1-21, jan/jun 2014. Disponível em: < https://revistas.ufpi.br/index.php/raj/article/view/3327< Acesso em: 30 out. 2019.

DORTIER, Jean-François. Dicionário de Ciências Humanas. 1 ed. São Paulo: Martins Fontes, 2010.

GUALDA, Diego de Lima. Individualismo Holista: uma articulação crítica do pensamento político de Charles Taylor. 2009. Dissertação (Mestrado em Ciência Política) - Faculdade de Filosofia, Letras e Ciências Humanas, Universidade de São Paulo, São Paulo, 2009. doi:10.11606/D.8.2009.tde-05022010-095325. Acesso em: 2019-10-30. 
HERRERA GÓMEZ, Manuel. Liberalismo versus comunitarismo. Seis voces para un debate y una propuesta. Navarra: Aranzadi, 2007.

HESSE, Konrad. Grundzüge des Verfassungsrechts der Bundesrepublik Deutschland. 19 Aufl. Heidelberg: C.F.Müller, 1993.

JAPIASSU, Hilton e MARCONDES, Danilo. Dicionário Básico de Filosofia. 3 ed. Rio de Janeiro: Jorge Zahar Editor, 2001.

LOPES, José Reinaldo de Lima. Ética e Direito - Um panorama às vésperas do século XXI. In: ANJOS, Márcio Fabri dos; LOPES, José Reinaldo de Lima (org.). Ética e Direito: Um Diálogo. $1^{\text {a }}$. ed. Aparecida: Santuário, 1996.

MORAIS, José Luis Bolzan de e BRUM, Guilherme Valle. Políticas públicas e jurisdição constitucional: entre direitos, deveres e desejos. Porto Alegre: Livraria do Advogado, 2016.

MORRISON, Wayne. Filosofia do direito. São Paulo: Martins Fontes, 2006.

OLIVEIRA, Isabel de Assis Ribeiro de. O mal-estar contemporâneo na perspectiva de Charles Taylor. Rev. bras. Ci. Soc., São Paulo, v. 21, n. 60, p. 135-145, Fev. 2006. Disponível em: $<$ http://www.scielo.br/scielo.php?script=sci_arttext\&pid=S0102-

69092006000100008\&lng=en\&nrm=iso>. Acesso em: 30 out. 2019. http://dx.doi.org/10.1590/S0102-69092006000100008.

RAWLS, John. Justiça como eqüidade: uma concepção política, não metafísica. Lua Nova, São Paulo, n. 25, p. 25-59, Abr. 1992. Disponível em: <http://www.scielo.br/scielo.php?script=sci_arttext\&pid=S010264451992000100003\&lng=en\&nrm=iso>. Acesso $\quad$ em: $20 \quad$ out. 2019. http://dx.doi.org/10.1590/S0102-64451992000100003

ROSA, Aléssio da. A ética das virtudes de Alasdair MacIntyre: implicações para a moralidade contemporânea. In.: Intuitio, Porto Alegre, v. 9, n. 2, p. 33-45, dez 2016, disponível em: $<$ http://revistaseletronicas.pucrs.br/ojs/index.php/intuitio/article/view/23690>. Acesso em 30 out. 2019. http://dx.doi.org/10.15448/1983-4012.2016.2.23690

SANDEL, Michael J. Justiça: o que é fazer a coisa certa? Rio de Janeiro: Civilização Brasileira, 2012.

SANTOS NETO, Arnaldo Bastos e HEINEN, Luana Renostro. As esferas de justiça de Michael Walzer como perspectiva de análise dos critérios de distribuição de bens sociais na jurisprudência recente do Superior Tribunal de Justiça (STJ). In: Novos Estudos Jurídicos, v. 17, n. 2, p. 287-304, mai-ago/2012. Disponível em: http://www6.univali.br/seer/index.php/nej/article/download/3974/2317.

SARLET, Ingo Wolfgang. Direitos fundamentais a prestações sociais e crise: algumas aproximações. In: Revista Espaço Jurídico, Joaçaba, v. 16, n. 2, p. 459-488, jul/dez 2015. Disponível em: $<$ http://editora.unoesc.edu.br/index.php/espacojuridico/article/view/6876/pdf $>$. Acesso em: 02 set. 2018. 
SCHMIDT, João Pedro. Comunidade e comunitarismo: considerações sobre a inovação da ordem sociopolítica. In: Ciências Sociais Unisinos, São Leopoldo, Vol. 47, N. 3, p. 300-313, set/dez 2011.

SILVA, Sideney Reinaldo da. A concepção comunitarista da democracia e a educação. In: Revista Eletrônica de Educação. São Carlos, SP: UFSCar, v.3, no. 1, p. 111-126, mai. 2009. Disponível em http://www.reveduc.ufscar.br.

SILVEIRA, Carlos Frederico, ROCHA, Felippe Augusto da Cruz; CARDOSO, Rafael Esteves. A ética da autenticidade na concepção multiculturalista de Charles Taylor. In.: Revista Lex Humana, Petrópolis, v. 4, n. 2, p. 14-34, 2012. Disponível em: < https://digitalisdsp.uc.pt/bitstream/10316.2/33742/1/LH4-2_artigo2.pdf?ln=pt-pt> Acesso em: 29 out. 2019.

STRECK, Lênio Luiz e MORAIS, José Luiz Bolzan de. Ciência Política e Teoria do Estado. Porto Alegre: Livraria do advogado, 2006.

TAYLOR, Charles. A Ética da Autenticidade. São Paulo: É Realizações, 2011.

WALZER, Michael. As esferas da justiça. São Paulo: Martins Fontes, 2003.

XIMENES, Julia Maurmann. Algumas reflexões sobre a incorporação do paradigma comunitarista na Constituição de 1988. Sequiência: Estudos Jurídicos e Políticos, Florianópolis, p. 47-66, set. 2010. ISSN 2177-7055. Disponível em: <https://periodicos.ufsc.br/index.php/sequencia/article/view/2177-7055.2008v29n57p47>.

Acesso em: 13 jan. 2019. doi:https://doi.org/10.5007/2177-7055.2008v29n57p47.

O supremo tribunal federal e a cidadania à luz da influência comunitarista. Rev. Direito GV, São Paulo, v. 6, n. 1, p. 119-141, June 2010. Available from $<$ http://www.scielo.br/scielo.php?script=sci_arttext\&pid=S1808-

24322010000100007\&lng=en\&nrm=iso>. Accesso em 22 abr. 2020 . https://doi.org/10.1590/S1808-24322010000100007.

Data de Submissão: 31/10/2019

Data de Aceite: 18/12/2020 